\title{
Effect of Calcium Carbonate on the Mechanical Properties and Microstructure of Red Clay
}

\author{
Lijie Chen, ${ }^{1,2}$ Xuejun Chen, ${ }^{1,2}$ Xin Yang, ${ }^{1,2}$ Pengyan Bi, ${ }^{1,2}$ Xiang Ding, ${ }^{1,2}$ Xiang Huang $\mathbb{D},{ }^{1,2}$ \\ and He Wang $\mathbb{D}^{1,3}$
}

${ }^{1}$ College of Civil and Architecture Engineering, Guilin University of Technology, Guilin 541004, China

${ }^{2}$ Guangxi Key Laboratory of New Energy and Building Energy Saving, Guilin 541004, China

${ }^{3}$ Army Engineering University, Nanjing 21001, China

Correspondence should be addressed to Xiang Huang; 6615031@glut.edu.cn and He Wang; wanghe502@126.com

Received 4 June 2020; Accepted 2 July 2020; Published 29 July 2020

Academic Editor: Zhaohui Li

Copyright (c) 2020 Lijie Chen et al. This is an open access article distributed under the Creative Commons Attribution License, which permits unrestricted use, distribution, and reproduction in any medium, provided the original work is properly cited.

The influence of precipitated calcium carbonate on the strength and microstructure of red clay was studied. Precipitated calcium carbonate was added to red clay at ratios of $0 \%, 5 \%, 10 \%, 15 \%$, and $20 \%$. Shear tests were carried out on the samples to observe the effect of calcium carbonate on the mechanical properties of red clay. The results showed that, with increasing calcium carbonate content, the strength of red clay first decreased and then increased. The maximum strength was obtained for the sample with $20 \%$ calcium carbonate. Scanning electron microscopy (SEM) was used to observe the changes in microstructure caused by addition of calcium carbonate. The pores and cracks analysis system (PCAS) was used to quantitatively characterize the microstructure changes detected in SEM images. The addition of calcium carbonate decreased the pore area and increased the total number of pores of red clay. The incorporation of calcium carbonate caused the red clay particles to agglomerate. The higher the calcium carbonate content, the stronger the agglomeration of red clay particles in the soil samples.

\section{Introduction}

Red clay is widely distributed in areas south of the Changjiang River in China, such as Guangxi, Guizhou, and Yunnan. Red clay is also locally distributed in Hunan, Hubei, Anhui, and Sichuan, mainly on plateaus, flats, hills, and low mountain slopes. Red clay develops in depressions and generally forms layers with a thickness of about $5-15 \mathrm{~m}$. Red clay is characterized by its high liquid limit, large porosity ratio, tendency to shrink and crack, and poor water stability. The high strength of red clay means that it is often mistaken as a good foundation soil. However, because of the high shrinkage of red clay, when its thickness variation in the horizontal direction is large, uneven settling can easily occur over time, leading to building damage [1]. To promote economic development, China has stepped up its efforts to construct infrastructure in its western region. During the construction process, red clay with poor engineering properties is frequently encountered. At present, red clay is typically replaced by other soils prior to building construction. However, red clay is widely distributed in the southwest area of China. The disposal of large amounts of red clay will substantially increase the engineering cost of building and cause damage to the ecological environment.

The strength of red clay can be increased by chemical modification, such as adding lime, cement, fly ash, and other inorganic cementing materials [2-4]. These additives can also lower the liquid-plastic limit and improve the water stability of red clay. However, these methods can cause environmental pollution and are costly. In addition, the production of ordinary Portland cement has considerable environmental effects because it is an energy-intensive industrial process, accounting for $5 \%-7 \%$ of global $\mathrm{CO}_{2}$ emission [5]. Many innovative approaches, such as liquid stabilizers [3, 6], have also been used to improve the properties of red clay. Calcium carbonate is widely distributed in regions with red clay, and it has a low mining cost and is easy to transport. The incorporation of precipitated 
calcium carbonate into red clay has been shown to affect the strength of red clay [7]. However, the microstructural changes of red clay induced by doping with calcium carbonate have not been quantitatively analyzed. The soil microstructure affects its engineering properties, so its characterization has attracted the attention of many researchers.

Scanning electron microscopy (SEM) is a useful tool to investigate soil structure and accelerate research progress. SEM can be used to observe natural and synthetic soil samples, allowing the relationship between soil microstructure and engineering properties to be analyzed. Gillot [8] used SEM to study the structure of fine grains of soil. Diamond [9] analyzed the microstructure of impact-compacted kaolinite and illite clays after drying by SEM. Collins and McGown [10] conducted a qualitative study on the microstructure of soil and proposed some concepts to explain their results.

With the development of computer science and technology, computer image processing technology has been used to analyze the microscopic pore structure of soil. Tovey and coworkers $[11,12]$ conducted a quantitative analysis of electron micrographs of soil structures and combined several image processing and analysis techniques to study the porosity of clay particles. Their work provided a new method to study the mineralogy and microstructure of soil. Shi [13] quantitively analyzed clay samples using a D/MAX III-A fabric automatic goniometer and Video lab image analysis system, from which a plan of soil microstructures was proposed. More image processing software was then developed [14, 15], which allowed the geometric and structure parameters of pores and particles to be calculated. The PCAS image processing software [16] can accurately calculate the geometric parameters of soil microstructure, including pore size and pore shape, providing quantitative statistics. The PCAS software has been successfully applied to the quantitative analysis of the microstructure of both rock and soil $[17,18]$.

In this paper, the effect of precipitated calcium carbonate on the mechanical properties of red clay is analyzed by direct shear tests. SEM observation, particle size analysis, and stacking measurements are carried out to study the effect of precipitated calcium carbonate content on the microstructure of red clay. PCAS software is used to quantitatively analyze the influence of calcium carbonate incorporation on the porosity, micropore structure, and particle size distribution of red clay.

\section{Materials and Methods}

2.1. Materials. The red clay used in this study was from Yanshan, Guilin, China, collected at a depth of $3 \mathrm{~m}$. The clay was brownish yellow mixed with brown in the plastic and hard plastic states. The parameters of the clay are listed in Table 1. Fine-grained soil with a particle size of less than $2 \mathrm{~mm}$ was obtained by drying and sieving the clay sample. The fine-grained red clay had a particle size ranging from
TABle 1: Physical parameters of red clay.

\begin{tabular}{lc}
\hline Parameters & Values \\
\hline Maximum dry density $\left(\mathrm{g} / \mathrm{cm}^{3}\right)$ & 1.67 \\
Optimal moisture content $(\%)$ & 22 \\
Liquid limit (\%) & 49.68 \\
Plastic limit (\%) & 37.53 \\
Plasticity index (\%) & 12.15 \\
Specific gravity & 2.75 \\
\hline
\end{tabular}

1.63 to $282.06 \mu \mathrm{m}$ (Figure $1(\mathrm{a})$ ). The precipitated calcium carbonate consisted of spindle-shaped particles with sizes ranging from 0.2 to $90 \mu \mathrm{m}$ (Figure $1(\mathrm{~b})$ ).

2.2. Mechanical Testing. Calcium carbonate was blended into the fine-grained red clay at mass ratios of $0 \%, 5 \%, 10 \%$, $15 \%$, and $20 \%$. The samples were thoroughly stirred and then sprayed with pure water to give a moisture content of $22 \%$. The samples were shaped into cylinders with a length of $61.8 \mathrm{~mm}$, diameter of $20 \mathrm{~mm}$, and dry density of $1.4 \mathrm{~g} / \mathrm{cm}^{3}$. The shear rate of the direct shear test was $0.8 \mathrm{~mm} / \mathrm{min}$. Shear tests were carried out under vertical pressures of 100, 200, 300 , and $400 \mathrm{kPa}$.

2.3. SEM Analysis. The red clay combined with precipitated calcium carbonate was made into a cylinder with a length of $10 \mathrm{~mm}$ and diameter of $10 \mathrm{~mm}$, frozen in liquid nitrogen for $15 \mathrm{~min}$, and then vacuum-dried for $24 \mathrm{~h}$ in a lowtemperature vacuum machine. The sample was broken into pieces, which were attached to an SEM support with conductive tape, coated with metal, and then observed by field-emission SEM (Carl Zeiss). The magnification range of the field-emission SEM was between $12 \mathrm{x}$ and 1,000,000x, and the maximum diameter of the measurable sample was $25 \mathrm{~mm}$.

2.3.1. Quantitative Analysis of Pore Structure. PCAS software developed by Liu et al. [16], which is a commercial software for analyzing the pore structure of soil in highresolution SEM images, was used to analyze the calcium carbonate-doped red clay samples. PCAS software has previously been used to analyze the fractures and pores of clay minerals $[19,20]$.

The pore area and length analyzed by the PCAS software were calculated using pixels and converted to actual values by image resolution using equations (1) and (2):

$$
\begin{gathered}
S_{f}=\frac{S_{P}}{P^{2}}, \\
L_{f}=\frac{L_{P}}{P},
\end{gathered}
$$

where $S_{f}$ is the actual area, $S_{p}$ is the pixel area, $L_{f}$ is the actual length, $L_{p}$ is the pixel length, and $P$ is the pixel resolution.

The fractal dimension $\left(D_{f}\right)$ is used to measure shape irregularities. In this study, PCAS software was used to calculate $D_{f}$ of the pores of the calcium carbonate-doped red 


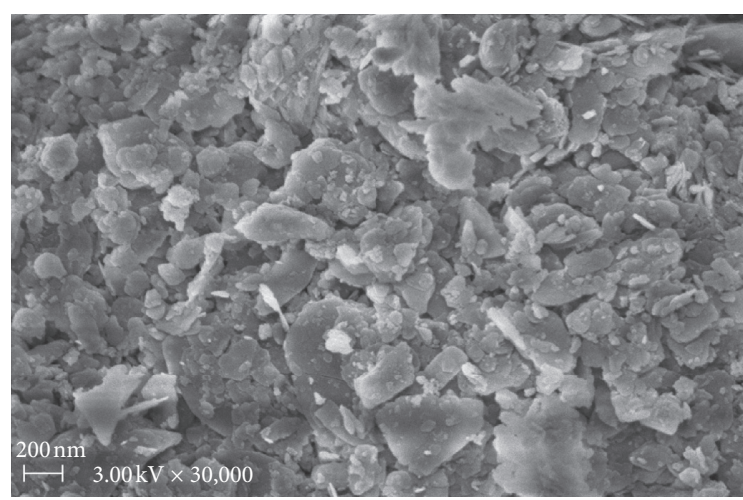

(a)

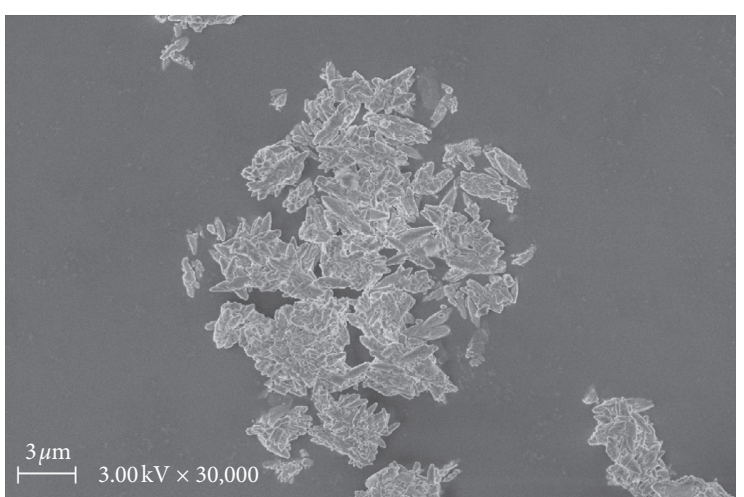

(b)

FIGURE 1: SEM images of (a) red clay and (b) precipitated calcium carbonate.

clay samples and quantitatively analyze the influence of calcium carbonate on the pore structure of red clay. The relationship between $D_{f}[15]$ and the pore perimeter $(c)$ and pore area $(s)$ can be expressed as

$$
\log (c)=\frac{D_{f}}{2 \log s}+c_{1}
$$

where $c_{1}$ is a constant. The relationship between the complexity of the pore and its area is evaluated by the areaperimeter method, which generally gives a value within the interval $[21,22]$.

The complexity of the pore properties can be quantified by the shape factor $\left(f_{f}\right)$. By calculating $f_{f}$, the changes caused by the incorporation of precipitated calcium carbonate can be analyzed. $f_{f}$ is calculated as [16]

$$
f_{f}=\frac{4 \pi s}{c^{2}}
$$

$f_{f}$ for a perfect circle and square are 1 and 0.785 , respectively. The $f_{f}$ values of a material are within the interval of $[0,1]$.

The probability entropy can be used to reflect the pore space of red clay. For the two-dimensional analysis, the interval of the arrangement, $[0, n]$, of the aggregate is divided into equal parts of $n$, and the probability of the pore assembly on the $i$ th part is $P i$. Then, $H$ is the probability entropy of the pore structure arrangement state, which can be calculated using the following equation [18]:

$$
H=-\sum_{i}^{n} P_{i} \log _{n}\left(P_{i}\right)
$$

In this study, $n=18$; that is, the orientation angle is between $0^{\circ}$ and $180^{\circ}$. $H$ is a statistical parameter that describes the arrangement of pore structure in the red clay samples and is within the interval $[0,1]$. When $H$ is 0 , the direction of all pores is the same. When $H$ approaches 0 , the pore arrangement is ordered, and the pore direction is inconsistent. In contrast, the closer the $H$ to 1 , the weaker the orientation of the pores, i.e., the more random the pore direction.

\section{Results and Discussion}

3.1. Mechanical Properties. The direct shear test results (Figure 2) revealed that the shear strength of red clay decreased first and then increased with rising calcium carbonate content. Under the action of $100 \mathrm{kPa}$ of vertical pressure, the strength of the sample with $5 \%$ calcium carbonate was lower than that of the undoped red clay. With increasing calcium carbonate content above 5\%, the shear strength of the samples gradually increased. The maximum shear strength was observed for the red clay sample with a calcium carbonate content of $20 \%$. A similar behavior was observed at different vertical pressures. The greater the vertical pressure, the larger the degree to which calcium carbonate increased the shear strength of red clay. For example, under the action of $400 \mathrm{kPa}$ of vertical pressure, $15 \%$ calcium carbonate increased the shear strength of red clay by 1.34 times, and $20 \%$ calcium carbonate raised the shear strength of red clay by $158 \%$.

Figure 3 shows that as the calcium carbonate content of the red clay samples increases, the cohesion of red clay decreases. The internal friction angle $(\varphi)$ was the smallest for the sample containing $5 \%$ calcium carbonate. When the doping content of calcium carbonate exceeded 5\%, $\varphi$ was positively correlated with the amount of calcium carbonate, indicating that the addition of calcium carbonate can increase the friction between the red clay particles.

\subsection{Pore Structure Analysis of Calcium Carbonate-Doped Red Clay}

3.2.1. Pore Morphology. SEM was used to observe and analyze the soil samples to study the effect of calcium carbonate doping on the pores and microstructure of red clay. The results are shown in Figures 4-7. As the calcium carbonate doping content increases, the red clay particles become more disperse. Figure 4 shows an SEM image of the undoped red clay at 30000x magnification. In this image, most of the red clay particles are lamellar, and the particle distribution is irregular.

Comparing Figures 4 with 6 indicates that the particles of the red clay samples doped with different contents of 


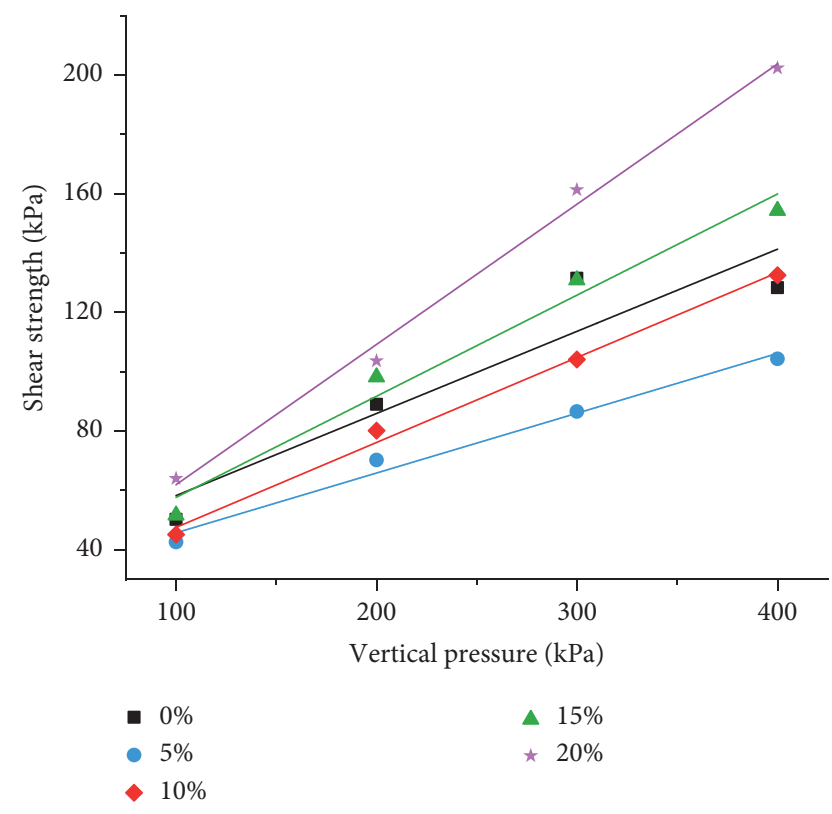

FIGURE 2: Shear strength of red clay samples with different calcium carbonate contents.

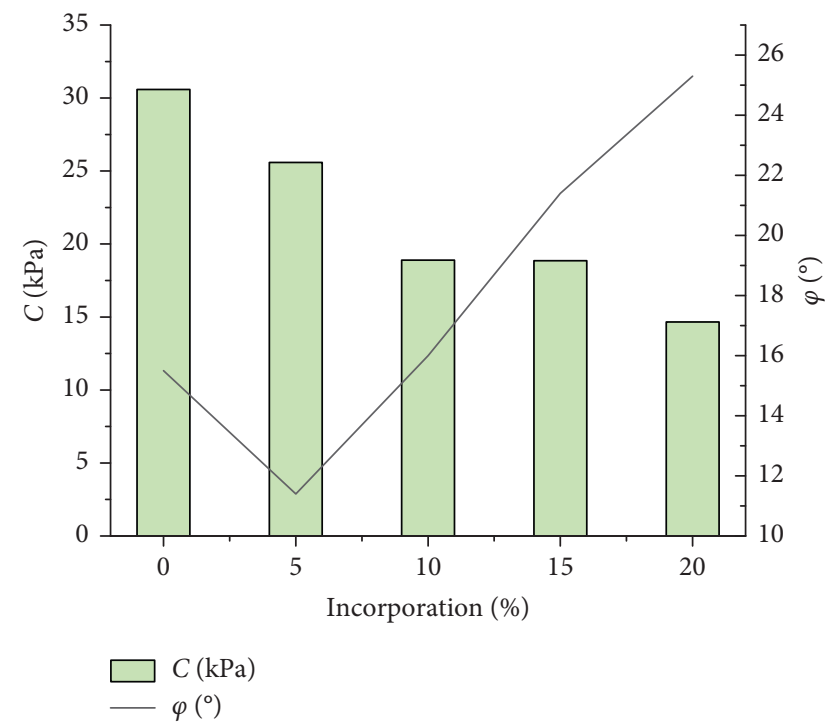

Figure 3: Cohesion $(C)$ and internal friction angles $(\varphi)$ of red clay samples doped with different contents of calcium carbonate.

calcium carbonate do not have specific shapes. The distribution of soil particles tends to be random in the sample doped with $15 \%$ calcium carbonate (Figure 5). However, it can be clearly seen that the structure becomes loose when the calcium carbonate doping content is 20\% (Figure 6). Figures 1(a) and 1(b) show that the spindle-shaped calcium carbonate particles and red clay mineral particles have obviously different shapes, and the calcium carbonate particles are larger than the soil particles. When calcium carbonate is incorporated into red clay, spindle-shaped calcium carbonate particles are embedded in the lamellar soil layers (Figure 7), which destroys the original lamellar

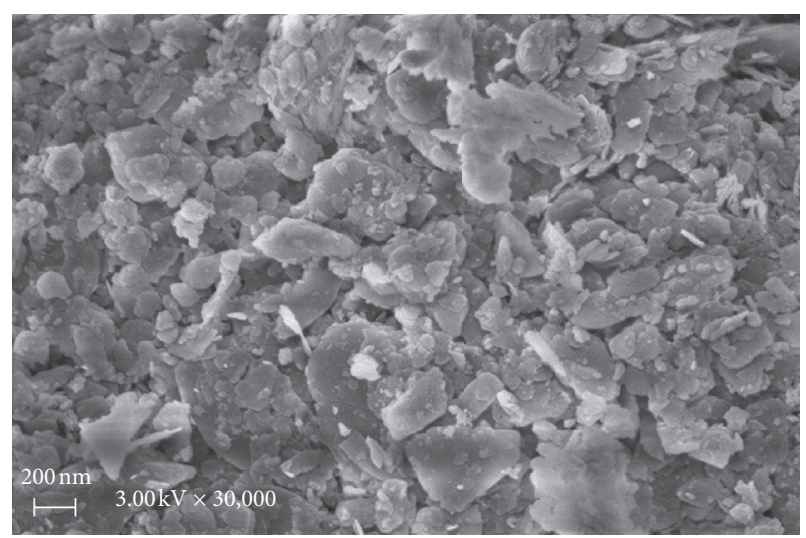

FIGURE 4: SEM image of red clay without calcium carbonate $(0 \%)$.

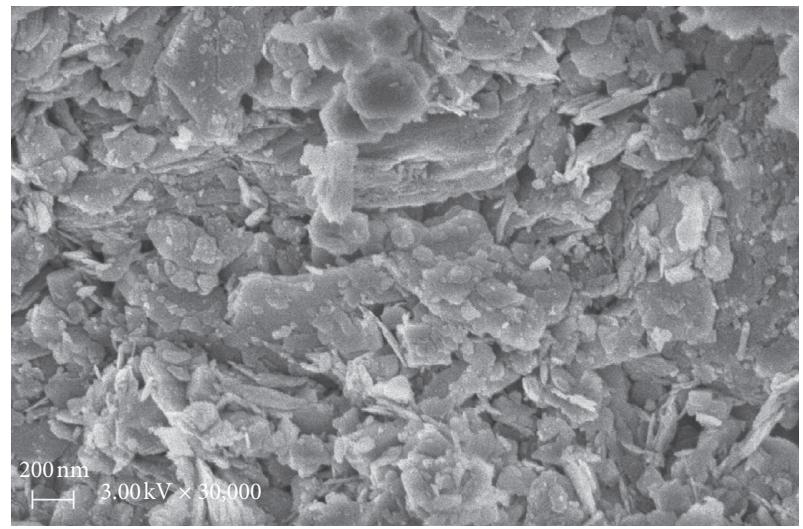

FIGURE 5: SEM image of $15 \%$ calcium carbonate-doped red clay.

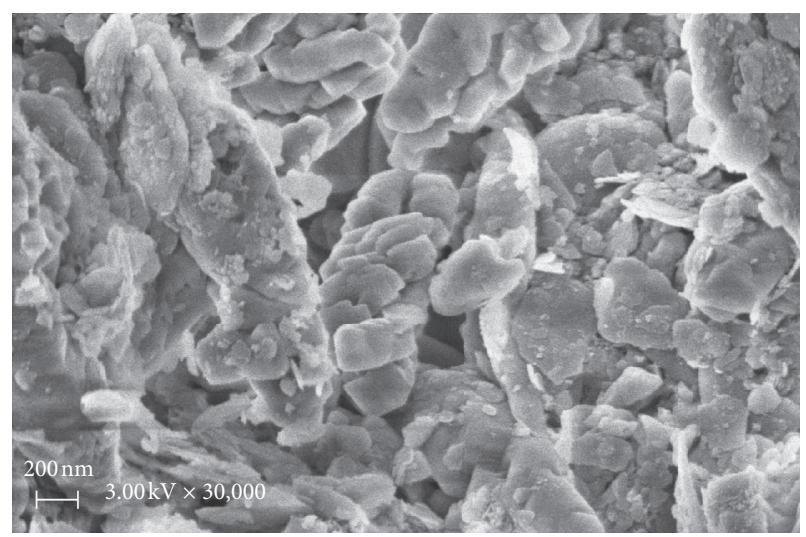

FIGURE 6: SEM image of $20 \%$ calcium carbonate-doped red clay.

structure of the red clay, causing the sample structure to become looser. Moreover, the greater the amount of calcium carbonate, the more obvious the structural change of the red clay. This is also the reason why the strength of the red clay decreased after calcium carbonate addition. However, when the amount of calcium carbonate was large enough, the effect of friction became more important than that of the loose structure, so the strength of the samples increased. 


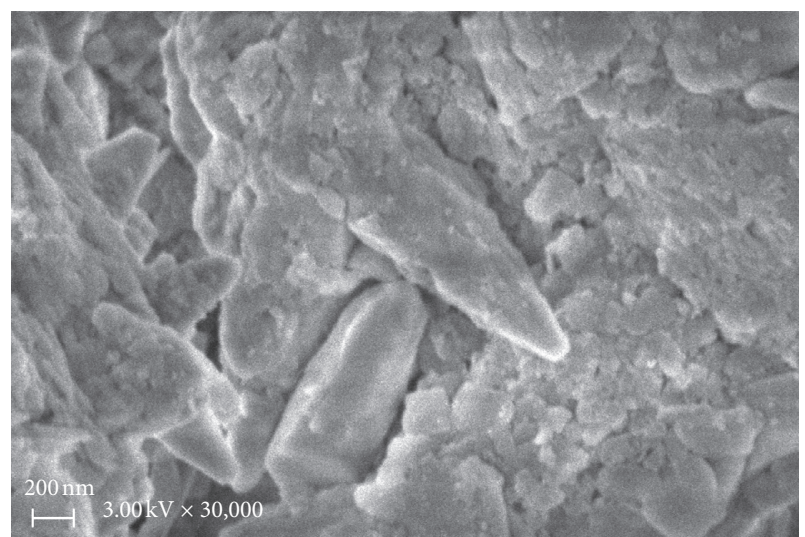

FiguRE 7: SEM image of $20 \%$ calcium carbonate-doped red clay.

3.2.2. Quantitative Analysis of Pore Structure. The pores of soil samples doped with different contents of calcium carbonate were analyzed by the PCAS software. The minimum pore threshold was 50 pixels, and the closed radius was 2 pixels. For each soil sample, five SEM images at the same magnification $(30,000 x)$ were selected, and then average values were determined. The geometric parameters of the pores and soil particles were calculated using equations (4) and (5). The area of each pixel point after conversion was $12.69 \mathrm{~nm}^{2}$, and the length of each pixel was $3.563 \mathrm{~nm}$.

The pore number and area determined from the statistical analysis of five SEM images for each sample are summarized in Table 2. Doping with calcium carbonate caused the number of pores in red clay to increase up to the maximum value of 679.8 for the sample with $10 \%$ calcium carbonate. The porosity of the samples increased with the amount of calcium carbonate. The highest porosity was obtained for the sample with $20 \%$ calcium carbonate, which was 1.3 times larger than the porosity of the undoped red clay. The addition of calcium carbonate substantially lowered the maximum pore area and average pore area of red clay. All doping contents of calcium carbonate had effects on the maximum pore area and average pore area of red clay, indicating that calcium carbonate can fill some of the large pores of red clay and make the pore area relatively uniform.

Table 2 reveals that $D_{f}$ was between 1.205 and 1.236 for the samples with different calcium carbonate contents. The pore shape was complicated, and $D_{f}$ did not change markedly after the incorporation of precipitated calcium carbonate. The calcium carbonate content of the samples had no apparent effect on the shape of the pores. The $f_{f}$ values of the soil were between 0.400 and 0.367 , which are much smaller than the $f_{f}$ of 0.785 for a square. The edges of the pore structures are complicated, and the incorporation of precipitated calcium carbonate did not make the sides of the pores smooth. The influence of the precipitated calcium carbonate on the pore structure of red clay was limited. For the samples with different calcium carbonate contents, $H$ of the pores in red clay is close to 1 , indicating that the soil pores have no orientation. As the doping content of calcium carbonate increases to $15 \%, H$ of the samples gets closer to 1 ,
TABLE 2: Soil and pore parameters obtained by PCAS software.

\begin{tabular}{lccccc}
\hline Parameter (\%) & 0 & 5 & 10 & 15 & 20 \\
\hline Pore number & 433.6 & 488.8 & 679.8 & 600.8 & 495.2 \\
Porosity (\%) & 21.55 & 22.11 & 23.86 & 24.09 & 28.15 \\
Maximum region area $\left(\mu \mathrm{m}^{2}\right)$ & 1.639 & 0.224 & 0.154 & 0.234 & 0.209 \\
Average region area $\left(\mu \mathrm{m}^{2}\right)$ & 0.016 & 0.004 & 0.003 & 0.004 & 0.005 \\
Average form factor & 0.400 & 0.402 & 0.367 & 0.369 & 0.367 \\
Probability entropy & 0.979 & 0.984 & 0.988 & 0.989 & 0.986 \\
Fractal dimension & 1.231 & 1.236 & 1.205 & 1.228 & 1.218 \\
\hline
\end{tabular}

showing that calcium carbonate caused the pores to become more disordered.

According to the International Association of Pure and Applied Chemistry [23], pores with a diameter of less than $2 \mathrm{~nm}$ are defined as micropores, pores with a diameter between 2 and $50 \mathrm{~nm}$ are defined as mesopores, and pores that are larger than $50 \mathrm{~nm}$ in diameter are defined as macropores. In our study, the smallest identifiable pore diameter was $25 \mathrm{~nm}$, so the calcium carbonate-doped red clay samples contain mesopores and macropores. The pore size distributions of the samples are shown in Figure 8. Up to a calcium carbonate content of $10 \%$, the total number of pores in the soil samples increased. The doping content of calcium carbonate had little effect on the number of macropores, whereas it influenced the number of mesopores. It is considered that the added calcium carbonate filled some of the large pores, thus changing macropores into several mesopores, which led to the notable change in the number of mesopores and increased the total number of pores. However, the fluctuation of macropores with changing calcium carbonate content was small.

\subsection{Influence of Calcium Carbonate Doping on the Grain Size} Distribution of Red Clay. The grain size distributions of the samples are plotted in Figure 9. The particle size of the precipitated calcium carbonate was between 0.2 and $90 \mu \mathrm{m}$ and that of the red clay was 0.2 to $282 \mu \mathrm{m}$. The particle size distributions show that as the amount of calcium carbonate increased, the number of particles with a diameter larger than $282 \mu \mathrm{m}$ increased. This phenomenon may be caused by the added calcium carbonate inducing aggregation of red clay particles, yielding newly formed particle much larger than the added calcium carbonate particles. The calcium carbonate particles could fill some of the macropores of the soil particles, which lowers the porosity of the red clay.

The nonuniformity coefficient $\left(C_{u}\right)$ is used to indicate the grain composition of soil samples. When $C_{u}$ is small, the slope of the grain size distribution curve is very steep, the soil particles are relatively uniform, and the grain size gradation is poor. When $C_{u}$ is large, the particle size gradation curve is gentle, indicating that the grain size gradation is favorable. $C_{u}$ was calculated using the following equation:

$$
C_{u}=\frac{d_{60}}{d_{10}}
$$




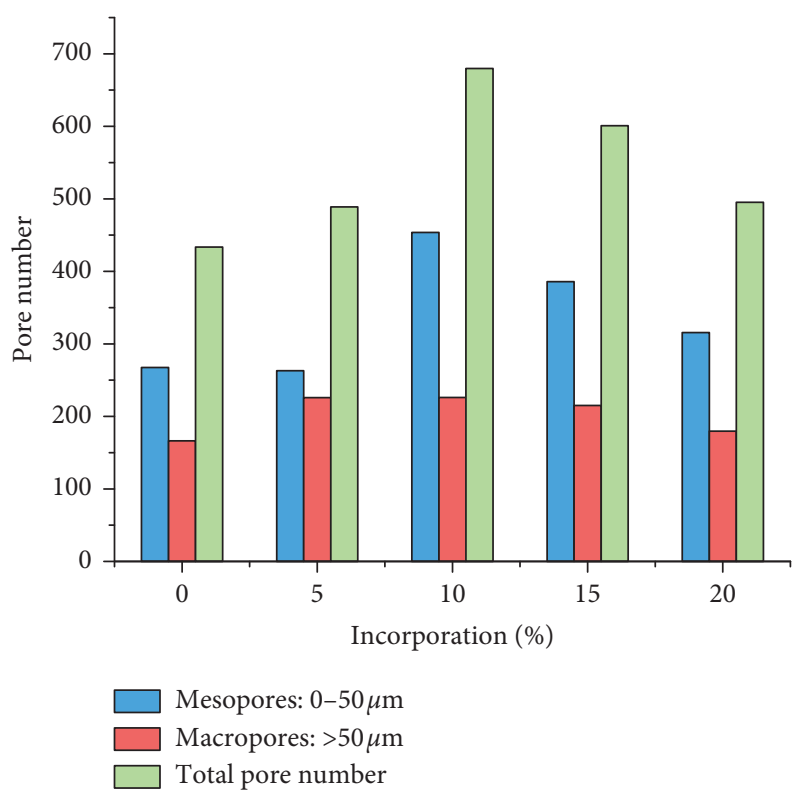

FIGURE 8: Distributions of mesopores and macropores in the calcium carbonate-doped red clay samples with different calcium carbonate contents.

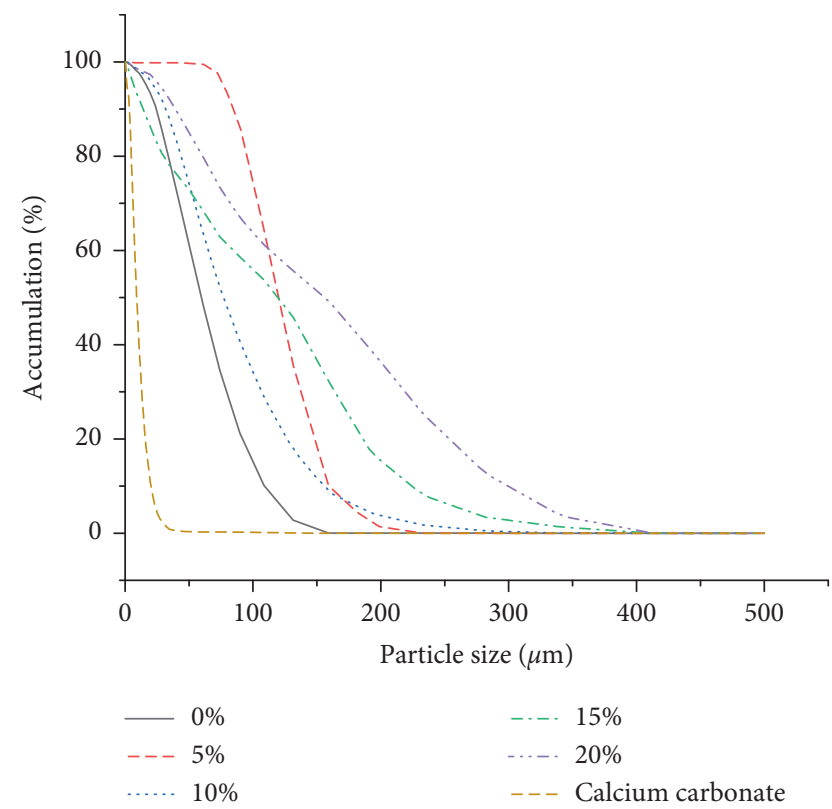

Figure 9: Grain size distributions of red clay samples doped with different contents of calcium carbonate.

where $d_{60}$ is the confined particle size with $60 \%$ of the soil particles finer than this size and $d_{10}$ is the effective particle size with $10 \%$ of the particles finer than this size.

The curvature coefficient $\left(C_{c}\right)$ represents the compositional characteristics of soil particles and was calculated using the following equation:

$$
C_{c}=\frac{\left(d_{30}\right)^{2}}{d_{10} \times d_{60}},
$$

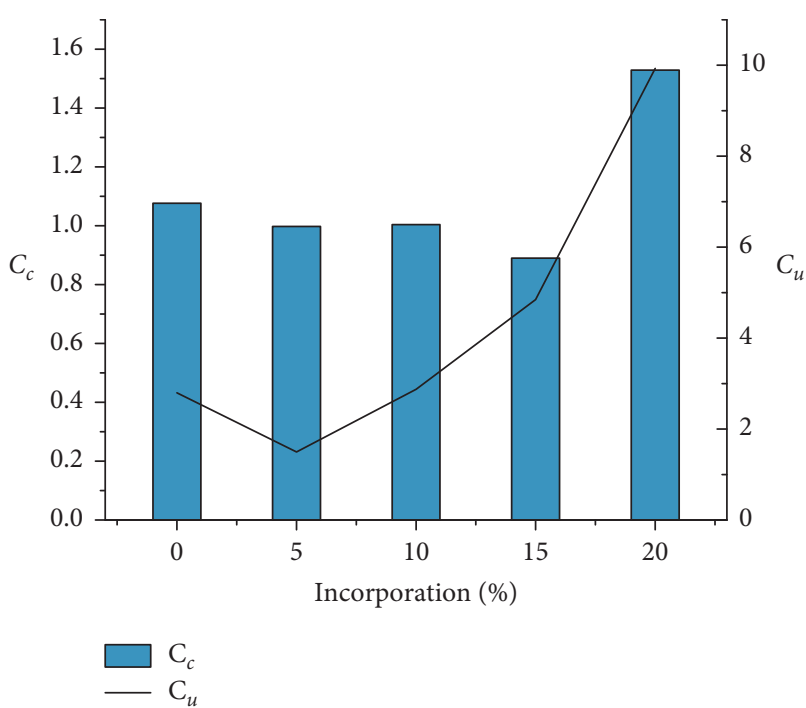

FIGURE 10: Particle size grading curve of red clay samples doped with different contents of calcium carbonate.

where $d_{30}$ is the particle size corresponding to $30 \%$ of the ordinate on the particle size gradation curve. When $C_{u} \geq 5$, and $C_{c}=1-3$, the gradation is suitable. If the gradation does not meet both these conditions at the same time, the gradation is poor.

Figure 10 shows that $C_{u}$ of the red clay is 2.80 and its $C_{c}$ is 1.08 , which means that it is a poorly graded soil. $C_{u}$ of the red clay samples increases with the doping content of calcium carbonate, illustrating that calcium carbonate modifies the grain size distribution of the soil samples. The addition of less than $15 \%$ calcium carbonate had little effect on $C_{c}$ of the samples. The addition of $20 \%$ calcium carbonate increased $C_{c}$, making it a well-graded soil. Therefore, the addition of $20 \%$ calcium carbonate improved the particle size gradation of red clay and its shear strength.

3.4. Bulk Density Measurements. Figure 11 shows the results of the stacking test of the samples. With the increasing addition of calcium carbonate up to $15 \%$, the loose density of the soil samples decreased markedly. When the calcium carbonate content was $20 \%$, the loose density of the soil sample increased slightly. It can be considered that when the amount of calcium carbonate added is greater than $15 \%$, calcium carbonate has little effect on the loose density of the soil sample. This result is also consistent with the SEM analysis. That is, increasing the calcium carbonate content of the soil samples increases their pore content.

\section{Conclusions}

The mechanical properties of red clay doped with calcium carbonate first weakened and then strengthened with increasing calcium carbonate content. The maximum shear strength was obtained for the red clay sample doped with $20 \%$ calcium carbonate. As the amount of calcium carbonate increased, the cohesion of red clay decreased and the internal friction angle first decreased and then increased, with the 


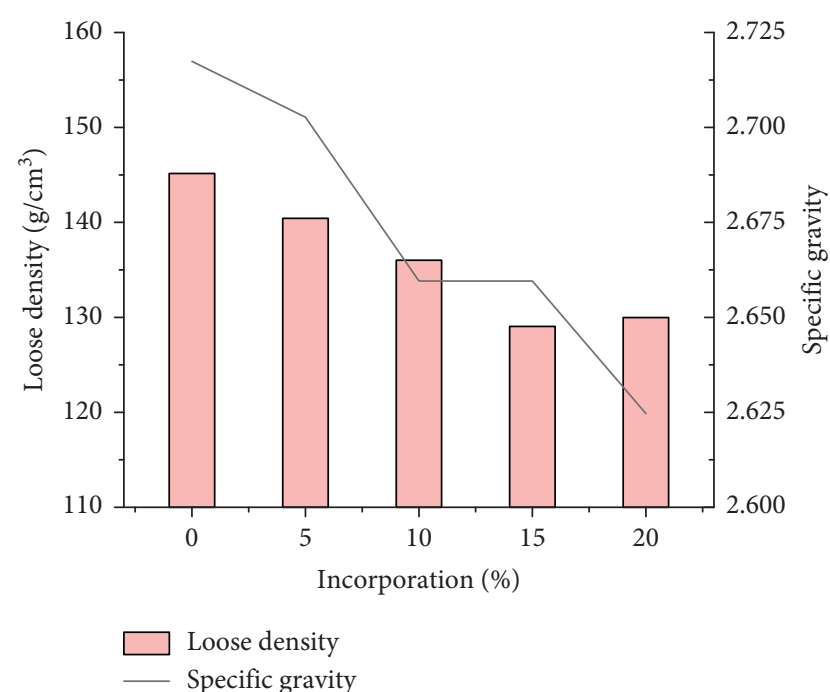

FIGURE 11: Loose density and specific gravity of red clay samples doped with different contents of calcium carbonate.

inflection point at $5 \%$ calcium carbonate. Adding calcium carbonate to red clay caused considerable changes of the microstructure of red clay, including substantial changes of porosity. The porosity of the calcium carbonate-doped red clay samples was positively correlated with the calcium carbonate content. The density of calcium carbonate is lower than that of red clay, and the specific gravity of the samples decreased with increasing content of calcium carbonate. The observed decrease of bulk density further proved that the incorporation of calcium carbonate strongly affected the microstructure of red clay, lowering its loose density and increasing its porosity.

\section{Data Availability}

The data used to support the findings of this study are available from the corresponding author upon request.

\section{Conflicts of Interest}

The authors declare that there are no conflicts of interest regarding the publication of this paper.

\section{Acknowledgments}

This research was supported by the National Natural Science Foundation of China (grant nos. 41762022 and 41967037).

\section{References}

[1] B. D'Angelo, A. Bruand, J. Qin et al., "Origin of the high sensitivity of Chinese red clay soils to drought: significance of the clay characteristics," Geoderma, vol. 223-225, pp. 46-53, 2014.

[2] J. Z. Li, L. C. Zhuo, and X. Ni, "Behavior of cemented reticulate red clay," Advanced Materials Research, vol. 446-449, pp. 1666-1669, 2012.

[3] J. S. Tingle and R. L. Santoni, "Stabilization of clay soils with nontraditional additives," in Proceedings of the 8th
International Conference on Low Volume Roads, pp. A72A84, Reno, NV, USA, June 2003.

[4] F. G. Bell, "Lime stabilization of clay minerals and soils," Engineering Geology, vol. 42, no. 4, pp. 223-237, 1996.

[5] S. Pourakbar and B. K. Huat, "A review of alternatives traditional cementitious binders for engineering improvement of soils," International Journal of Geotechnical Engineering, vol. 11, no. 2, pp. 206-216, 2017.

[6] N. Latifi, A. Marto, and A. Eisazadeh, "Analysis of strength development in non-traditional liquid additive-stabilized laterite soil from macro-and micro-structural considerations," Environmental Earth Sciences, vol. 73, no. 3, pp. 1133-1141, 2015.

[7] X. J. Chen, J. L. Chen, Y. Song, H. Chen, and H. Wang, "Experimental study on strength characteristics of red clay under different particle size of calcium carbonate," in Proceedings of the International Symposium on Energy Geotechnics, Lausanne, Switzerland, September 2019.

[8] J. E. Gillott, "Study of the fabric of fine-grained sediments with the scanning electron microscope," SEPM Journal of Sedimentary Research, vol. 39, pp. 90-105, 1969.

[9] S. Diamond, "Microstructure and pore structure of impactcompacted clays," Clays and Clay Minerals, vol. 19, no. 4, pp. 239-249, 1971.

[10] K. Collins and A. McGown, "The form and function of microfabric features in a variety of natural soils," Géotechnique, vol. 24, no. 2, pp. 223-254, 1974.

[11] N. K. Tovey, D. H. Krinsley, D. L. Dent, and W. M. Corbett, "Techniques to quantitatively study the microfabric of soils," Geoderma, vol. 53, no. 3-4, pp. 217-235, 1992.

[12] N. K. Tovey and M. W. Hounslow, "Quantitative microporosity and orientation analysis in soils and sediments," Journal of the Geological Society, vol. 152, no. 1, pp. 119-129, 1995.

[13] B. Shi, "Quantitative research on the orientation of microstructures of clayey soil," Acta Geologica Sinica (English Edition), vol. 1, pp. 36-44, 1997.

[14] M. R. Cox and M. Budhu, "A practical approach to grain shape quantification," Engineering Geology, vol. 96, no. 1-2, pp. 1-16, 2008.

[15] A. Dathe, S. Eins, J. Niemeyer, and G. Gerold, "The surface fractal dimension of the soil-pore interface as measured by image analysis," Geoderma, vol. 103, no. 1-2, pp. 203-229, 2001.

[16] C. Liu, B. Shi, J. Zhou, and C. Tang, "Quantification and characterization of microporosity by image processing, geometric measurement and statistical methods: application on SEM images of clay materials," Applied Clay Science, vol. 54, no. 1, pp. 97-106, 2011.

[17] K. Jiao, S. Yao, C. Liu et al., "The characterization and quantitative analysis of nanopores in unconventional gas reservoirs utilizing FESEM-FIB and image processing: an example from the lower Silurian Longmaxi Shale, upper Yangtze region, China," International Journal of Coal Geology, vol. 128-129, pp. 1-11, 2014.

[18] E. N. Yargicoglu, B. Y. Sadasivam, K. R. Reddy, and K. Spokas, "Physical and chemical characterization of waste wood derived biochars," Waste Management, vol. 36, pp. 256-268, 2015.

[19] Y.-L. Qu, W.-K. Ni, F.-J. Niu, Y.-H. Mu, G.-L. Chen, and J. Luo, "Mechanical and electrical properties of coarse-grained soil affected by cyclic freeze-thaw in high cold regions," Journal of Central South University, vol. 27, no. 3, pp. 853-866, 2020 . 
[20] L. Liu, J. Xin, and C. Huan, "Pore and strength characteristics of cemented paste backfill using sulphide tailings: effect of sulphur content," Construction and Building Materials, vol. 237, no. 13, 2020.

[21] M. L. Cao, X. Ming, and K. Y. He, "Effect of macro-, microand nano-calcium carbonate on properties of cementitious composites a review," Materials, vol. 12, p. 20, 2019.

[22] Y. Boyjoo, V. K. Pareek, and J. Liu, "Synthesis of micro and nano-sized calcium carbonate particles and their applications," Journal of Materials Chemistry A, vol. 2, no. 35, pp. 14270-14288, 2014.

[23] A. D. McNaught and A. Wilkinson, IUPAC Compendium of Chemical Terminology, "The "Gold Book"”, Blackwell Scientific Publications, Oxford, UK, 2019. 